\title{
Anca Gheaus, Gideon Calder and Jurgen De Wispelaere, The Routledge Handbook of the Philosophy of Childhood and Children, Routledge: 2019; 440 pp.: ISBN 9780367733889
}

Reviewed by JASMINA JERANT ${ }^{1}$

The fact that children are greatly puzzled about the world around them is no news. However, the idea that children can, due to their naturally conditioned philosophical openness, pose philosophical questions that are relevant and very valuable to us all has only recently been embraced by scholars. This and, for example, children's rights to their sexuality as well as to work instead of going to school are just a few of the triggering points evoking further interest in reading this much-needed collection of essays, which finally provides in one place an

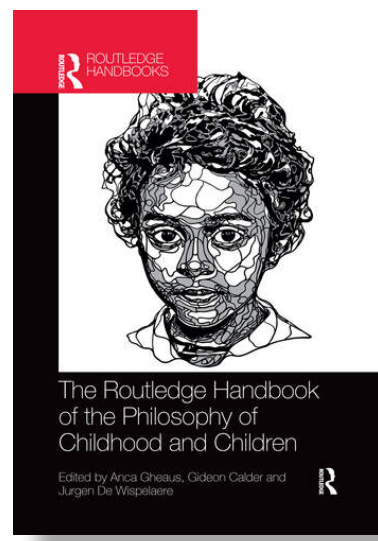
introductory insight into the state-of-the-art contemporary debate surrounding the philosophy of children.

The Routledge Handbook of the Philosophy of Childhood and Children comprises thirty-six essays collected by three editors. Anca Gheaus, a political philosopher interested in justice and the normative significance of personal relationships, has published numerous journal articles and book chapters and is currently writing a monograph on child-centred childrearing. Gideon Calder, a social and political philosopher, has authored or edited ten books, including How Inequality Runs in Families, and is a co-editor of the Routledge journal Ethics and Social Welfare. Jurgen De Wispelaere, whose research interests are at the intersection of political theory and public policy, is a Political Economy Research Fellow with the ISRF and a Policy Fellow at the Institute for Policy Research.

With well-distributed topics that have been largely set aside for most of the history of philosophy, the editors have structured a handbook that provides timely guidance to the world of neglected questions that have only recently

1 Faculty of Education, Universtiy of Ljubljana, Slovenia; jasmina.jerant@gmail.com. 
been gaining attention. As Gheaus points out in the Introduction to the book, "in moral and political philosophy, the literature on childrearing, and especially on the parent-child relations, has been multiplying at an exponential rate during the past four decades" (p. 1). Hence, the collection presents some, but not all, of these themes in one place. The editors' aim, however, was "also to draw attention to the many issues that are still under-explored and, therefore, to encourage further research" (p. 2). With many of the chapters setting grounds for further debate, they have succeeded in doing so.

The editors have divided the work of forty-four international contributors from the diverse backgrounds of philosophy, political science, law, social policy, cognitive neuroscience, anthropology, political economy, healthcare, art, paediatrics, bioethics, social epistemology, developmental psychology, etc., into five main sections that provide an overview of the current debate on the nature of children (Part I - Chapters 1 to 5), their moral status (Part II - Chapters 6 to 12), parenting and family (Part III - Chapters 13 to 21), the relationship between children and society (Part IV - Chapters 22 to 27), and the relationship between children and the state (Part V - Chapters 28 to 36). Each of the chapters reveals a different topic related to the philosophy of childhood and children, crossing the individual fields from which the chapter authors come.

As the Handbook is so extensive on a range of topics, it is impossible to present each and every one of them in depth in the limited space available. I have therefore chosen a few essays that might be of particular interest to readers of the CEPS Journal, as they touch upon the questions of education, schooling and knowledge to some degree. In addition, I mention a couple of other essays not directly related to education that address themes largely neglected in philosophy.

The first section, or Part I, entitled Being a child, consists of five essays discussing the nature of children. The essays are related to children's development of knowledge, thinking and behaviour, as well as the nature of artistic creativity. In Epistemology: knowledge in childhood, the authors explore notions of knowledge in child development and the nature of children's knowledge, or how infants and young children possess knowledge. Fabrice Clément and Melissa Koenig argue that children possess and use metacognitive inquiry. Also on the possession of knowledge, M. J. Cain's essay Language and communication: evidence from studying children focuses on how children acquire the meaning of words, develop knowledge of their first language and build vocabulary. In contrast to the usual view of the matter, Cain defends the existence of a distinctive innate endowment that powers us in early age with abstract concepts and a metaphysical perspective, and not only learning mechanisms, 
as otherwise claimed.

It is worth mentioning that these two essays deal with very young children and even infants, and that there are only two other essays in Part I with an emphasis on children's age or developmental phase. Furthermore, most of the book's essays omit an acknowledgement of differentiation in children's age. This might represent something of a shortcoming, as age does make a difference in how children behave or what they need. Moreover, Gheaus notes that age-related differences in ability and level of autonomy "have normative and practical significance" (p. 2).

The first of the two chapters that devote attention to a particular age group is The science of the adolescent brain and its cultural implications by Suparna Choudhury and Nancy Ferranti. The authors demonstrate that it is necessary to depart from the popular conception of the teen brain that has been fuelled through the neuromythology of the last twenty years and further boosted via popular culture, consequently creating a misleading image of adolescents. Choudhury and Ferrant blame this brain-based model of adolescence for stigmatising young people through biological reductionism. Hence, the authors argue for turning instead towards social neuroscience and critically oriented cultural neuroscience. Both of these disciplines prove that social and cultural contexts impact the development and activity of the human brain. In fact, they cause an actual difference in brain development that can be seen in intersectionally different groups of adolescents.

The second chapter that deals with an age-specific group of children is on Philosophical thinking in childhood. Jana Mohr Lone focuses on children between the ages of 5 and 11 and their ability to engage in meaningful philosophical inquiry. Children possess a common, naturally inborn epistemic openness that is especially attributed to them. Besides presenting evidence on how children at this age are capable of engaging in conversations on philosophical topics, the author calls attention to what they have to say. Ignoring them is, argues Mohr Lone, a special case of epistemic injustice, as we deny them the instrumental and intrinsic benefits. The instrumental value of philosophy for children shows, firstly, with improved scores on Cognitive Ability Tests, and secondly, with increased critical consciousness and analytical and critical thinking. If prejudiced in regard to philosophy, children lose in terms of intrinsic benefit, as philosophical wondering enhances their experience of childhood. Furthermore, as we lose the epistemic openness with age, children's philosophical thoughts strengthen philosophy's intrinsic value for adults as well. Our own thinking and philosophical inquiry is enriched with children's sense for magic possibility. To some extent, the essay also presents a case for 
implementing classes in philosophy at an early age, in primary schools, not just in rare examples of grammar schools. This is a thought worthy of acknowledgment, particularly at a time when the whole of society needs to find ways to re-establish the ability for critical consciousness, and analytical and critical thinking in future generations.

Part II of the book focuses on Childhood and moral status through seven essays: The moral status of children, The value of childhood, Childhood and wellbeing, Children's rights, Childhood and autonomy, Paternalism towards children, and The age of consent. Part III, as its title Parents and children indicates, departs from a sole focus on children and turns to parents and family as well. The debate on parents and children is composed of nine essays on Reasons to have children - or not, The right to parent, The good parent, Parental partiality, The composition of the family, Parental licensing and discrimination, Ethical challenges for adoption regimes, Gender and the family, and Filial duties.

Part IV, entitled Children in society, presents an overview of six debates focused on how we, as a society, ought to treat children. The debate spans the themes of race, disability, sexuality, animals, child labour, and the vulnerability of children. I highlight here the essay on Childhood and sexuality by Jennifer Epp and Samantha Brennan, which opens a theme that has been largely neglected in the history of philosophy. When sexuality in relation to children has been discussed in the past, the focus has usually been on children as victims of sexual abuse, while the chapter in the Handbook argues for children as independent agents. Moreover, the authors argue that from a particular perspective, sex and pleasure can also be the goods of childhood. For this reason, the authors appeal for child sexuality to also be considered when talking about children's well-being. Their essay opens the ground for more debates on this neglected yet sensitive topic in the current and future philosophy of childhood.

An equally thought-provoking essay in Part IV focuses on children and child labour. In his essay What's wrong with child labour? Philip Cook gives an answer that is the opposite to what we usually think: not everything. For some children, Cook argues, labour saves their life. Hence, work can sometimes be more beneficial to children, or even less harmful, than schooling. The author therefore states that philosophy still needs to answer two things in regard to schooling. Firstly, it needs to establish that schooling actually really does benefit children and their development. Secondly, if we look at the issue through the lens of our duty of benefiting children, philosophy needs to answer why, in fact, should schooling not simply be replaced with work, if work can, in some instances, benefit children more than schooling.

Schooling is in fact the main theme in the last section of the book, Part 
$\mathrm{V}$, which is dedicated to the question of the relationship between Children and the state. In her essay Schooling, Gina Schouten explores questions of school's justifiability and its coerciveness for children, parents and taxpayers. Schouten proposes that schooling should firstly promote the potential of students, then equalise the potential and, finally, prepare children for citizenship in a democratic, pluralistic society. The other eights essays in Part V focus on Childhood and the metric of justice, Children and political neutrality, The costs of children, Children and the care system, Children and health, Children and the right to vote, Children, crime and punishment, and Children and war.

The other essays that touch upon the question of education and schooling are the chapters on Childhood and disability, The good parent, Parental partiality, Children and political neutrality, and Children and race. Notwithstanding the variety of themes that go beyond education, each of the chapters of the Handbook will be of value to CEPS Journal readers interested in philosophical argumentation on distinct themes and intersections between philosophy and a range of other disciplines exploring children and childhood.

Whether a historical overview or more of an argumentative essay, each of the chapters provides an insightful introduction to the topic that might also be informative for the newcomer to the philosophy of childhood and children. Equally important, many of the chapters leave space for new questions and further research and discussion on what a child is, how to differentiate or value childhood in comparison to adulthood, and what we - either as parents, teachers, family, society or the state - owe children both as the unique individuals they are now, and as future adults.

Although there are shortcomings with chapters not being dedicated more narrowly to a particular age group, it is clear that we would need an entire book for each particular age group for each theme. Hence, we have at least received an introductory anchor that provides an overview of the literature and arguments in the philosophy of childhood and children for further research, as, with the current pandemic, more questions on how to treat children and what they deserve will arise in the decades to come. 